\title{
Influence of Microwave Irradiation on Hydrolysis Reaction of Sunflower Oil in Aqueous Emulsion
}

\author{
Nassima Mazouzi-Sennour*, François Henry \\ Equipe "Systèmes Polymères Complexes", Institut de Chimie et des Matériaux Paris-Est, UMR 7182 \\ CNRS-Université Paris-Est Créteil, Thiais, France \\ Email: "nassima_mazouzi@yahoo.fr
}

Received 14 December 2013; revised 21 January 2014; accepted 29 January 2014

Copyright $@ 2014$ by authors and Scientific Research Publishing Inc.

This work is licensed under the Creative Commons Attribution International License (CC BY). http://creativecommons.org/licenses/by/4.0/

(c) (i) Open Access

\begin{abstract}
Microwave irradiation (MW) has been widely applied as heating in chemical processing. It offers a clean, convenient and inexpensive method of heating which often results in higher yields and shorter reaction times. Here, we study the microwave heating influence on the hydrolysis of the triglyceride (sunflower oil) in aqueous emulsion catalyzed by using 4-dodecylbenzenesulfonic acid (DBSA). The progress of the hydrolysis reaction was determined by Fourier Transform Infrared spectroscopy (FTIR). The effects of temperature, reaction time and the catalyst nature and concentration on the hydrolysis reaction were investigated. The hydrolysis was carried out at temperatures ranging between $90^{\circ} \mathrm{C}$ and $150^{\circ} \mathrm{C}$. The polarity of the reaction medium accelerated this reaction.
\end{abstract}

\section{Keywords}

Microwave; 4-Dodecylbenzenesulfonic Acid; Hydrolysis Reaction; Sunflower Oil

\section{Introduction}

The hydrolysis of triglycerides contained in vegetable oils or animal fats is produced industrially from the reaction of vegetable oils or animal fats with superheated steam [1]. Different technologies have been used in industry. The most important are the batch autoclave process (the Twitchell process) [2] and the continuous process (the Colgate-Emery process) [3]. Currently, the reaction is carried out by the action of a steam in a countercurrent column at $100^{\circ} \mathrm{C}-260^{\circ} \mathrm{C}$ and $20-60$ bar [4], [5]. The reaction does not require the use of a catalyst, and af-

*Corresponding author.

How to cite this paper: Mazouzi-Sennour, N. and Henry, F. (2014) Influence of Microwave Irradiation on Hydrolysis Reaction of Sunflower Oil in Aqueous Emulsion. International Journal of Organic Chemistry, 4, 24-28.

http://dx.doi.org/10.4236/ijoc.2014.41004 
ter 1 to 3 hours, the conversion of triglycerides is about $98 \%$ - 99\% [6]. This reaction was also carried out in the subcritical water at $270^{\circ} \mathrm{C}-340^{\circ} \mathrm{C}$ and $130 \mathrm{bar}$ in a relatively short time $(10 \mathrm{~min})$ using oil/water molar ratio of $1 / 5$ [7]. More recently, supercritical carbon dioxide $\left(\mathrm{SC}-\mathrm{CO}_{2}\right)$ was used as hydrolysis medium to enhance the solubility of water in the oil phase (triglyceride) [8]. A conversion of $100 \%$ of triolein was achieved after 3 hours at $250^{\circ} \mathrm{C}$.

In milder conditions, hydrolysis of tricaprylin was carried out using solid acid catalysts at $110^{\circ} \mathrm{C}-150^{\circ} \mathrm{C}$ and atmospheric pressure in a semibatch reactor with continuous addition of water at low flow rates [9]. Hydrolysis in emulsion has been also studied [10]. Palm oil hydrolysis was carried out using a mixture of linear alkyl benzene sulfonate as anionic surfactant combined with $\left(\mathrm{H}_{2} \mathrm{SO}_{4}\right)$ as acid catalyst at different oil/water proportions below $100^{\circ} \mathrm{C}$. The use of a surfactant in combination with an acid catalyst allows the acceleration of the hydrolysis reaction [11].

In the recent years, considerable researches have been devoted to the application of microwave heating in chemistry [12]. This type of heating is more penetrative than the conventional one [13]. It offers a clean, convenient and inexpensive method of heating which often results in higher yields and shorter reaction times [14]. This process mainly depends on the specific polarity of molecules. Since water is polar it has good potential to absorb microwaves and to convert them into heat energy, consequently accelerating the reactions in an aqueous medium as compared to results obtained using conventional heating [15]-[17].

In this context, the aim of the present work is to study the hydrolysis reaction of sunflower oil carried out under microwave heating in aqueous emulsion using an anionic surfactant.

\section{Experimental Details}

\subsection{Chemicals Reagents}

Commercial sunflower oil was used without further purification. 4-dodecylbenzenesulfonic acid (DBSA, mixture of isomers 95\%) and sulfuric acid were purchased from Sigma Aldrich Chemicals. Deionized water was used.

\subsection{Materials}

Reactions were performed into commercial microwave (multimode reactor Synthos 3000, Anton-Paar) equipped with two magnetrons able to provide $1400 \mathrm{~W}$ of continuous MW power at $2.45 \mathrm{GHz}$. The control system supplied with the instrument allows working with either controlled temperature or irradiation power.

\subsection{Experimental Procedure}

The emulsion was prepared by adding $7.6 \mathrm{~mL}$ of water into $12 \mathrm{~g}$ of sunflower oil containing $0.4 \mathrm{~g}$ of DBSA with a magnetic stirrer, so that the water-to-oil ratio was $40 \%(\mathrm{w} / \mathrm{w})$. The mixture was exposed to ultrasounds during $90 \mathrm{~s}$ with 70\% of amplitude (Branson sonifier W450 digital) at ambient temperature. The emulsion was heated under microwaves. The microwave reactor was programmed to maintain a constant temperature by adjusting the applied power.

\subsection{Analysis}

\section{Infrared Spectroscopy}

Attenuated total reflection Fourier transform infrared (ATR-FTIR) spectra were run with a Brucker Tensor 27 DTGS spectrophotometer. The spectra were recorded between 4000 and $450 \mathrm{~cm}^{-1}$ with an average of 30 consecutive scans with a resolution of $4 \mathrm{~cm}^{-1}$.

The hydrolysis progress rate was determined by ATR-FTIR spectroscopy. The relative ester residual was calculated according to the following equation:

$$
f_{\text {residual ester }}(\%)=\frac{A_{\text {ester }}}{A_{\text {ester }}+A_{\text {acid }}}
$$

which allows to plot the normalized curve of the triglyceride hydrolysis. Where $A_{\text {ester }}$ corresponding to the integration of the $1730 \mathrm{~cm}^{-1}$ band resulting from the $\mathrm{C}=\mathrm{O}$ stretching vibration of ester group and $A_{\text {acid }}$ corresponding 
to the $1690 \mathrm{~cm}^{-1}$ band resulting from the $\mathrm{C}=\mathrm{O}$ stretching vibration of carboxylic acid group.

\section{Results and Discussion}

The hydrolysis reaction was carried out in emulsion at different temperatures using different proportions of surfactants with water-to-oil ratio of $40 \%(\mathrm{w} / \mathrm{w})$ (Table 1$)$.

The rate of hydrolysis reaction can be expressed by using a decreasing exponential according to the following equation:

$$
C_{t}=C_{0} \cdot e^{-k t}
$$

where $C_{t}$ is the concentration of the triglycerides during the reaction and $C_{0}$ is the concentration of triglycerides at the beginning of the reaction.

The results obtained by varying the temperature of the hydrolysis are presented in Figure 1 .

The curves were fitted by the linear-regression method using Origin software. Each curve represents the progress of the hydrolysis reaction over time at $110^{\circ} \mathrm{C}, 130^{\circ} \mathrm{C}$ and $150^{\circ} \mathrm{C}$ temperatures. It was then observed that the increase of temperature raises the rate constant of the chemical reaction (Table 2) and the equilibrium was reached more rapidly. This suggested that higher temperatures would enhance the hydrolysis reaction.

The effect of varying catalyst level on the hydrolysis at $150^{\circ} \mathrm{C}$ is shown in Figure 2. It was observed that decreasing of the catalyst concentration does not affect the kinetic of the reaction. Furthermore, no hydrolysis was observed in reactions conducted at $150^{\circ} \mathrm{C}$ and $230^{\circ} \mathrm{C}$ (run 9, 10) under microwave heating using anionic surfactant (DBSNa) but without using a catalyst.

The surfactant adsorbs on the droplets surface leading to large interfaces between water and oil and allowing better contact between both phases. On the other hand, water has a high dielectric loss $\left(\varepsilon^{\prime \prime}=19.1\right)$ and good potential to absorb microwaves and to convert them into heat energy. However, these conditions were not sufficient to lead to hydrolysis.

The other parameter we investigated was the nature of catalyst. DBSA has been replaced by another anionic surfactant (DBSNa) using stoichiometric amounts of $\mathrm{H}_{2} \mathrm{SO}_{4}$ as catalyst. The reaction was conducted at $150^{\circ} \mathrm{C}$. The progress of the hydrolysis reaction is shown in Figure 3. Thus, when using DBSA, the reaction kinetic is slightly faster than when using DBSNa. This emphasizes the catalytic effect of DBSA. Contrary to the sulfuric acid which is soluble in aqueous phase, the DBSA is hydrophobic. So, it is either adsorbed on the surface or located in the core of the particles, consequently catalyzing more efficiently the hydrolysis reaction.

Therefore, the surfactant polar heads (dipole ionizable $\mathrm{SO}_{3}{ }^{-}, \mathrm{H}^{+}$) located on the surface of droplets containing triglyceride and the presence of water owning high dielectric loss $\left(\varepsilon^{\prime \prime}=19.1\right)$ are favorable to the penetration of electromagnetic waves providing good conditions for optimal microwave heating.

\section{Conclusion}

Hydrolysis reaction was conducted on sunflower oil under microwaves (MW) heating in aqueous media. The influence of temperature and the catalyst nature and concentration were investigated. The obtained results high-

Table 1. Conditions of the sunflower oil hydrolysis in aqueous emulsion.

\begin{tabular}{ccccc}
\hline Run & Surfactant & \% Surfactant $\left(\mathrm{w} / \mathrm{w} \mathrm{H}_{2} \mathrm{O}\right)$ & $\mathrm{T}\left({ }^{\circ} \mathrm{C}\right)$ & Observation \\
\hline 1 & DBSA & $5 \%$ & 90 & hydrolysis \\
2 & DBSA & $5 \%$ & 110 & hydrolysis \\
3 & hBSA & $5 \%$ & 130 & hydrolysis \\
4 & $\mathrm{DBSA}$ & $5 \%$ & 150 & hydrolysis \\
5 & $\mathrm{DBSA}$ & $2.5 \%$ & 150 & hydrolysis \\
6 & $\mathrm{DBSA}$ & $1.25 \%$ & 150 & hydrolysis \\
7 & $\mathrm{DBSA}$ & $5 \%$ & 220 & hydrolysis \\
$8^{*}$ & $\mathrm{DBSNa} / \mathrm{H}_{2} \mathrm{SO}_{4}$ & $2.5 \%$ & 150 & No reaction \\
9 & $\mathrm{DBSNa}$ & $2.5 \%$ & 150 & No reaction \\
10 & $\mathrm{DBSNa}$ & $5 \%$ & 230 & \\
\hline
\end{tabular}

"Using $0.6 \mathrm{~g}$ of $\mathrm{H}_{2} \mathrm{SO}_{4}$ added to oil, $0.5 \mathrm{~g}$ of DBSNa and $7.6 \mathrm{~g}$ of water. 
Table 1. Reaction rate constant of sunflower oil hydrolysis in aqueous emulsion at different temperatures.

\begin{tabular}{cc}
\hline $\mathrm{T}\left({ }^{\circ} \mathrm{C}\right)$ & Reaction rate constant $\left(\mathrm{min}^{-1}\right)$ \\
\hline 90 & $13.6 \times 10^{-3}$ \\
110 & $13.8 \times 10^{-3}$ \\
130 & $4.2 \times 10^{-2}$ \\
150 & $1.1 \times 10^{-1}$ \\
\hline
\end{tabular}

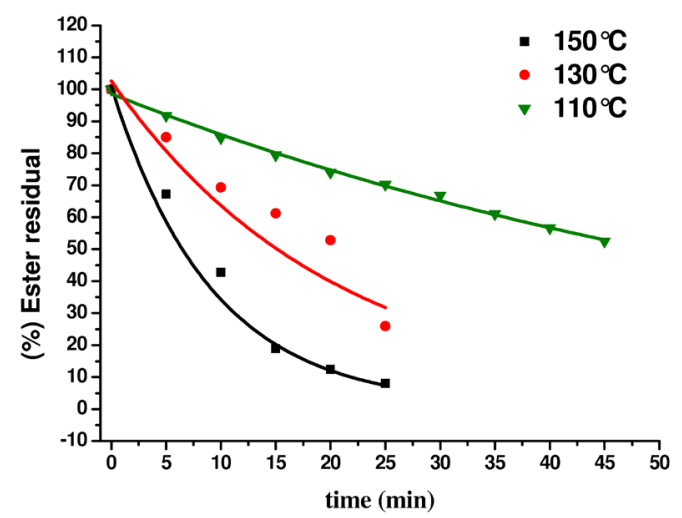

Figure 1. Effect of temperature on the hydrolysis of sunflower oil.

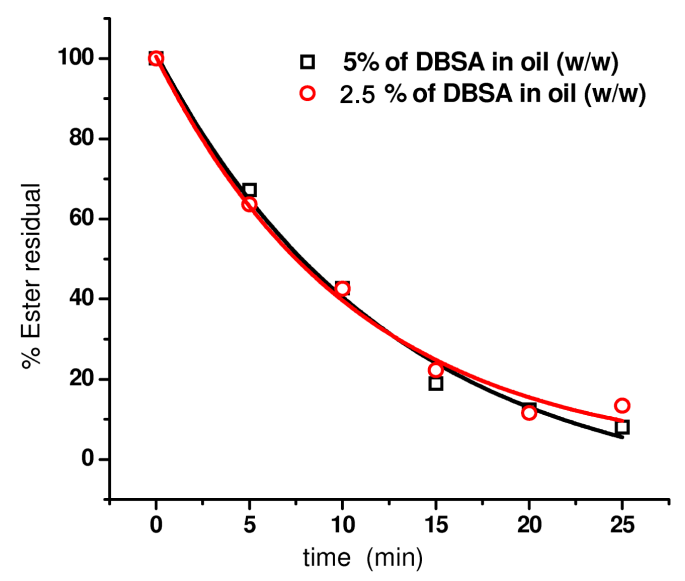

Figure 2. Effect of catalyst level on the hydrolysis of sunflower oil using $40 / 60$ (w/w) water-to-oil ratio at $150^{\circ} \mathrm{C}$.

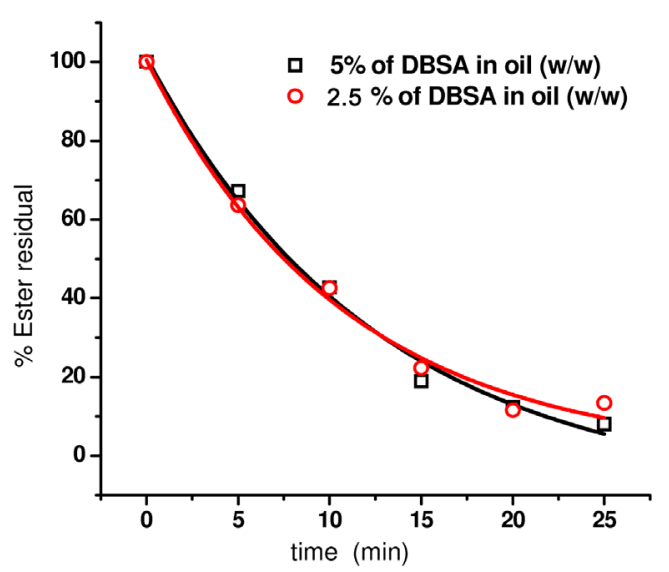

Figure 3. Comparison between using DBSA and $\mathrm{DBSNa} / \mathrm{H}_{2} \mathrm{SO}_{4}$ on the hydrolysis of sunflower oil at $150^{\circ} \mathrm{C}$. 
lighted that:

1) The increase of temperature raises the rate constant of the chemical reaction;

2) Temperature does not influence the hydrolysis reaction in the absence of catalyst;

3) The hydrolysis reaction is accelerated when using hydrophobic catalyst.

From these results, we conclude that under optimum conditions of catalyst concentration and maximum water absorption, MW heating is optimum and consequently hydrolysis is accelerated.

\section{Acknowledgements}

The authors are thankful for financial support from ONIDOL Company.

\section{References}

[1] Sonntag, N.O.V. (1979) Fat Splitting. Journal of the American Oil Chemists' Society, 56, 729A-732A.

[2] Twitchell, E. (1898) Twitchell Process of Decomposing Fats or Oils into Fatty Acids and Glycerin. US Patent No. 601603 A.

[3] Barnebey, H.L. and Brown, A.C. (1948) Continuous Fat Splitting Plants Using the Colgate-Emery Process. Journal of the American Oil Chemists' Society, 25, 95-99.

[4] Ittner, H.M. (1949) Counter Current Hydrolysis of Fat. Patent US No. 2480471.

[5] Patil, T.A., Butala, D.N., Raghunathan, T.S. and Shankar, H.S. (1988) Thermal Hydrolysis of Vegetable-Oils and Fats 1. Reaction-Kinetics. Industrial and Engineering Chemistry Research, 27, 727-735. http://dx.doi.org/10.1021/ie00077a001

[6] Riegel, E.R. and Kent, J.A. (2003) Riegel's Handbook of Industrial Chemistry. 10th Edition, Springer, Berlin.

[7] King, J.W., Holliday, R.L. and List, G.R. (1999) Hydrolysis of soybean oil in a subcritical water flow reactor. Green Chemistry, 1, 261-264. http://dx.doi.org/10.1039/a908861j

[8] Fujita, K. and Himi, M. (1995) Nippon Kagaku Kaishi. J-STAGE, 1, 79-82. http://dx.doi.org/10.1246/nikkashi.1995.79

[9] Ngaosuwan, K., Lotero, E., Suwannakarn, K., Goodwin, J.G. and Praserthdam, P. (2009) Hydrolysis of Triglycerides Using Solid Acid Catalysts. Industrial \& Engineering Chemistry Research, 48, 4757-4767. http://dx.doi.org/10.1021/ie8013988

[10] Anozie, A.N. and Dzobo, J.M. (2006) Kinetics of the Hydrolysis of Palm Oil and Palm Kernel Oil. Industrial and Engineering Chemistry Research, 45, 1604-1612. http://dx.doi.org/10.1021/ie0508076

[11] Twitchell, E. (1900) Benzenestearosulphonic Acid and Other Sulphonic Acids Containing the Stearic Radical. Journal of the American Chemical Society, 22, 22-26. http://dx.doi.org/10.1021/ja02039a006

[12] Hoogenboom, R. and Schubert, U.S. (2007) Microwave-Assisted Polymer Synthesis: Recent Developments in a Rapidly Expanding Field of Research. Macromolecular Rapid Communications, 28, 368-386. http://dx.doi.org/10.1002/marc.200600749

[13] Gabriel, C., Gabriel, S., Grant, E.H., Halstead, B.S.J. and Mingos, D.M.P. (1998) Dielectric Parameters Relevant to Microwave Dielectric Heating. Chemical Society Reviews, 27, 213-223. http://dx.doi.org/10.1039/a827213z

[14] Roussy, G. and Pearce, J.A. (1995) Foundations and Industrial Applications of Microwave and Radio Frequency Fields. Physical and Chemical Processes, John Wiley \& Sons, Chichester.

[15] Polshettiwar, V. and Varma, R.S. (2008) Aqueous Microwave Chemistry: A Clean and Green Synthetic Tool for Rapid Drug Discovery. Chemical Society Reviews, 37, 1546-1557. http://dx.doi.org/10.1039/b716534j

[16] Dallinger, D. and Kappe, C.O. (2007) Microwave-Assisted Synthesis in Water as Solvent. Chemical Reviews, 107, 2563-2591.

[17] Polshettiwar, V. and Varma, R.S. (2010) Aqueous Microwave Assisted Chemistry: Synthesis and Catalysis: Fundamentals of Aqueous. RSC Green Chemistry No. 7, Royal Society of Chemistry, 1-8. 